(C) Inra/Elsevier, Paris

Original article

\title{
Validity of leaf areas and angles estimated in a beech forest from analysis of gap frequencies, using hemispherical photographs and a plant canopy analyzer
}

\author{
Isabelle Planchais ${ }^{\mathrm{a}, \mathrm{b}}$, Jean-Yves Pontailler ${ }^{\mathrm{a}^{*}}$ \\ a'Laboratoire d'écophysiologie végétale, CNRS, bâtiment 362, université Paris-Sud, 91405 Orsay cedex, France \\ bDépartement des recherches techniques, Office national des forêts, boulevard de Constance, 77300 Fontainebleau cedex, France
}

(Received 11 December 1997; accepted 1 July 1998)

\begin{abstract}
Using both a Li-Cor Plant Canopy Analyzer (PCA) and the hemispherical photographs technique, we measured the gap fraction in two young beech pole stands of known leaf tip angle distribution. The average contact number at various zenith angles $(K(\theta)$ function) was determined and leaf area index was calculated using the method proposed previously. The following cases were examined: 1) data from PCA using five, four or three rings, 2) data from hemispherical photographs, arranged in rings, and divided into azimuth sectors $\left(90,45\right.$ and $\left.22.5^{\circ}\right)$ or averaged over azimuth $\left(360^{\circ}\right)$. These results were compared with a semi-direct estimation of the leaf area index derived from allometric relationships established at tree level. We also compared the $G(\theta)$ functions calculated using direct measurements of the leaf tip angle distribution with those deduced from transmittance data. The two indirect techniques gave the same estimation of the gap fraction at all zenith angles. When data were processed using the random model (averaged over azimuth), the PCA and photographs provided the same values of leaf area index, these values being considerably lower than those from allometric relationships $(-25 \%)$. When data from hemispherical photographs were divided into narrow azimuth sectors $\left(22.5^{\circ}\right)$, assuming a quasi-random model, the estimate of leaf area index was improved, but remained about $10 \%$ below the allometric estimates. Leaf area index estimated using the random model was found to be $75 \%$ of that estimated using allometric relationships. It is shown that the underestimation of the leaf area index observed considering all five rings on the PCA is due to an inappropriate use of the random model. It is also shown that the increase in leaf area index that was observed when neglecting one or two rings (PCA) was caused by an important error in the estimation of the slope of the function $K(\theta)$. We quantified this bias which depends on the leaf angle distribution within the canopy. Errors made on $K$ function by the PCA are often compensated by an arbitrary omission of one or two rings. The consequences of neglecting these rings are discussed, together with the respective interest of both techniques. (C) Inra/Elsevier, Paris.)
\end{abstract}

LAI-2000 Plant Canopy Analyzer / hemispherical photography / canopy structural parameters / tree allometrics / beech / Fagus sylvatica

Résumé - Estimation des surfaces et angles foliaires dans une hêtraie par deux techniques indirectes : la photographie hémisphérique et le Plant Canopy Analyzer. Nous avons mesuré la fraction de trouées dans deux gaulis de hêtres en utilisant deux techniques différentes : la photographie hémisphérique et le Plant Canopy Analyzer de Li-Cor (LAI-2000). Le nombre moyen de contacts dans plusieurs directions zénithales (fonction $K(\theta)$ ) a été déterminé, puis l'indice foliaire a été calculé en utilisant la méthode proposée par Lang [14]. Nous avons effectué ce calcul pour : 1) le PCA (Li-Cor), en utilisant trois, quatre ou cinq anneaux, 2) les photographies hémisphériques subdivisées en anneaux concentriques puis en secteurs azimutaux de $360,90,45$ ou $22,5^{\circ}$. Les résultats ont été comparés à une estimation semi-directe de l'indice foliaire basée sur des relations allométriques à l'échelle de l'arbre.

Les deux techniques indirectes fournissent la même estimation de la fraction de trouées dans chaque anneau. Lorsque les données sont traitées avec le modèle aléatoire, le PCA et les photographies donnent la même valeur d'indice foliaire, laquelle est nettement plus

\footnotetext{
* Correspondence and reprints

jean-yves.pontailler@eco.u-psud.fr
} 
faible que celle estimée par allométrie $(-25 \%)$. Lorsque les photographies sont traitées en prenant en compte l'hétérogénéité directionnelle de la fraction de trouées dans chaque couronne (traitement par secteurs azimutaux de $22,5^{\circ}$ ), $1^{\prime}$ estimation de l'indice foliaire est meilleure, sans toutefois atteindre la valeur obtenue par allométrie $(-10 \%)$.

Notre étude confirme que la sous-estimation fréquemment observée en utilisant le PCA avec cinq anneaux s'explique par l'utilisation inadéquate du modèle aléatoire. Sur un plan théorique, nous montrons que l'omission d'un ou des deux anneaux inférieurs, lors du traitement des données PCA, amène un biais dans l'estimation de la pente de la fonction $K(\theta)$. L'erreur commise dépend de la distribution d'inclinaison foliaire. Dans le cas très fréquent d'une distribution planophile du feuillage, l'erreur commise par l'omission arbitraire d'un ou plusieurs anneaux est globalement compensée par la sous-estimation d'indice foliaire due à l'utilisation du modèle aléatoire. Nous discutons des conséquences du mode d'exploitation des données, et de l'intérêt respectif des deux techniques utilisées. (@ Inra/Elsevier, Paris.)

\section{Li-Cor LAI-2000 / photographie hémisphérique / structure du couvert / relations allométriques / hêtre / Fagus sylvatica}

\section{INTRODUCTION}

Leaf area index $(L)$ is a variable of major importance in productivity, radiative transfer and remote-sensing ecological studies. Direct methods of measuring leaf area index are tedious and time-consuming, especially on forest stands. As a result, numerous indirect methods were developed to estimate the leaf area index of canopies [8, $18,20]$.

These methods are based on the gap fraction concept, defined as the probability for a light beam from a given direction to go through the canopy without being intercepted by foliage. A number of estimations of the gap fraction, at several zenith angles, enables a calculation of the major structural parameters $[13,20]$ : leaf area index, mean leaf angle and, occasionally, foliage dispersion.

Gap fraction is derived from measured transmitted radiation below the canopy on sunny days (Ceptometer, Decagon Devices, Pullman, WA, USA and Demon, CSIRO Land and Water, Canberra, Australia) or in overcast conditions (LAI-2000 Plant Canopy Analyzer, LiCor, Lincoln, NE, USA), or more directly by mapping the canopy gaps by the means of hemispherical photographs $[1,3]$. The LAI-2000 Plant Canopy Analyzer (named PCA hereafter) simultaneously estimates the gap fraction on five concentric rings centred on the zenith and consequently provides a rapid determination of the structural parameters of the canopy, requiring a single transect performed in overcast conditions [9].

The estimations obtained using these methods are not totally satisfying $[4,10,18]$. Estimated values of $L$ are highly correlated to direct measurements but they often show a trend to underestimate that varies according to both technique and site. Consequently, these methods appear to be practical tools to assess temporal or spatial relative variation in $L$ but require an extra calibration for absolute accuracy. In the case of the PCA, the cause of this underestimation is not obvious, the estimates varying largely according to the number of rings that are considered: neglecting one or two of the lowest rings reduces the discrepancies between the PCA's and direct measurements. In European deciduous forests, Dufrêne and Bréda [9] observed an underestimation of about $30 \%$ when using all rings and $11 \%$ when using the four upper rings, the best fit being obtained when considering the three upper rings only. Chason et al. [4] reported an underestimation of 45, 33, 22 and $17 \%$ with five, four, three and two rings, respectively, in a mixed oak-hickory forest. These low values have often been attributed to an overestimation of the gap fraction by the lowest rings. Such a bias could result from a response of the PCA to foliage scattering $[6,9,10]$. In other respects, errors due to an incorrect reference or to the presence of direct solar radiation could also cause an underestimation of $L$.

From a practical point of view, it is often difficult to obtain a reliable reference (covering all zenith angles) when using a PCA, especially in forest areas. For this reason, authors who comment on the number of rings to be considered largely agree on the necessity to cancel the lowest ring but rarely discuss the origin of the frequently observed underestimation.

The aim of this study is to compare leaf area index estimations from the PCA and from hemispherical photographs in two young dense beech pole stands of known leaf angle distribution. This will enable us to fix the cause of the $L$ underestimation by the PCA, to discuss the consequences of deleting one or two rings and to enlarge upon the merits of both techniques.

\section{MATERIALS AND METHODS}

\subsection{Theory of leaf area index calculation}

Assuming a canopy to be an infinite number of randomly distributed black leaves, the leaf area index, $L$, is given by the equation:

$$
L G(\theta)=-\cos \theta \ln T(\theta)=K(\theta)
$$

where $T(\theta)$ is the gap frequency and corresponds to the probability that a beam at an angle $\theta$ to the vertical would 
cross the canopy without being intercepted. $G(\theta)$ is the projection of unit area of leaf in the considered direction $\theta$ on a plane normal to that direction. $K(\theta)$ is the contact number and is equal to the average number of contacts over a path length equal to the canopy height and $\cos \theta$ accounts for the increased optical length due to the zenith angle.

Lang [13] proposed a simple method for computing leaf area index, without requiring the leaf angle distribution and no need of all values of $K(\theta)$ for $\theta$ varying from 0 to $90^{\circ}$. He demonstrated that the $K(\theta)$ function is quasilinear:

$$
K(\theta)=\mathrm{a}+b \theta
$$

He showed that a simple solution for $L$ is obtained with equation 2. This is similar to interpolating a value of $K$ for $\theta$ equalling 1 radian, $G$ being close to 0.5 at this point:

$$
L=2(a+b)
$$

Equation 1 shows that the leaf area index is proportional to the logarithm of the transmission. Many authors emphasize the importance of calculating $K$ by averaging the logarithm of the transmission rather than the transmission itself $[4,14,26]$. The estimate of leaf area index from the averaged gap fraction (linear average) assumes that leaves are randomly distributed within the canopy, which can result in large errors [15], especially when the spatial variations of the leaf area index are noticeable. Using a logarithmic average is equivalent to applying the random model locally, in several sub-areas whose structure is considered as homogeneous. This quasi-random model [14] is far less restrictive than the assumption that the whole vegetation should be random, and provides a correctly weighted estimate of the average leaf area index, in the presence of large gaps.

\subsection{Site characteristics}

We studied two beech (Fagus sylvatica $\mathrm{L}$.) pole stands in the Compiègne forest $\left(2^{\circ} 50^{\prime} \mathrm{E}, 49^{\circ} 20^{\prime} \mathrm{N}\right.$, France). Mean stand height was 8.5 and $11 \mathrm{~m}$, and beech trees were 17 and 20 years old, respectively. In these plots, beech ( $95 \%$ of stems) forms a fully closed and homogeneous canopy. In each plot, a $60 \mathrm{~m}^{2}$ study area was delimited and all trees were measured (height and diameter at breast height). Basal area and stem density were found to be equal to $16.5 \mathrm{~m}^{2} \mathrm{ha}^{-1}$ and 9500 stems ha ${ }^{-1}$ in the first plot and $28 \mathrm{~m}^{2} \mathrm{ha}^{-1}$ and $7800 \mathrm{stems} \mathrm{ha}^{-1}$ in the second plot.

Leaf area index of both plots was determined using 1) tree allometrics, 2) a PCA and 3) hemispherical photographs. These latter measurements, performed during the leafy period (early September 1996), were based on light interception by leaves as well as woody parts. The resulting index will be referred to as $L$ for convenience, but has to be considered as a plant area index (PAI).

\subsection{Methods for leaf area index estimation}

\subsubsection{Semi-direct estimation}

Within the framework of a wider study on beech regeneration in the Compiègne forest, allometric relationships were established at shoot, branch and then at tree levels. Our sampling method was fairly identical to the three-stage sampling described by Gregoire et al. [11]. The 26 sampled trees ranged from 4 to $10 \mathrm{~m}$ and experienced different levels of competition for space. Twelve of the 26 sampled trees were located in the two plots in which the study was conducted. For each sampled tree, we measured the diameter at breast height $D_{b h}$, the total height, the height to the base of the live crown and the diameter and age of all branches.

The total leaf area of these 26 trees was determined using a three-step procedure: 1) At shoot level, a sample of 582 leafy shoots was collected in order to establish a relationship between shoot length and shoot leaf area. A planimeter (Delta- $T$ area meter, Delta- $T$ Devices, Cambridge, UK) was used to measure leaf area. 2) At branch level, a sample of 221 branches was collected. Allometric relationships between branch diameter and branch leaf area were established for four classes of branch age $(1-2,3-4,5-6$ years and 7 years and older), using the measured parameters of the branches (diameter, length of all the shoots) and the previously mentioned relationships at shoot level. 3) At tree level, the already mentioned relationship at branch level was used to estimate the total leaf area of the 26 sampled trees. A relationship between the tree basal area, the height to the base of the crown and the total leaf area was established. Finally, this latter relationship was used to calculate the total leaf area in the two surveyed plots, based on the individual size of all the trees within the plot.

\subsubsection{LAI-2000 Plant Canopy Analyzer}

The LAI 2000 Plant Canopy Analyzer is a portable instrument designed to measure diffuse light from several zenith angles. The sensor head is comprised of a 'fisheye' lens that focuses an image of the canopy on a silicon sensor having five detecting rings centred on the angles 7 , $23,38,53$ and $68^{\circ}$. The optical system operates in the blue region of the spectrum $(<490 \mathrm{~nm})$ to minimize lightscattering effects. Reference measurements make it possible to estimate, for each ring, a gap fraction computed 
as the ratio of light levels measured above and below the canopy. The spatial variability of the gap fraction is accounted in part by averaging $K$ values over a transect [26]. However, azimuth variation in transmission cannot be assessed since the PCA provides an averaged gap frequency, integrated over azimuth for each ring.

In each study area, ten measurements were taken in uniformly overcast sky conditions. A $270^{\circ}$ view cap was used to eliminate the image of the experimenter. Before that, and also immediately after, reference measurements were taken in a clearing which was large enough to provide a reliable reference for all five rings. The gap fractions were computed assuming a linear variation of incident radiation between the beginning and the end of the experiment. The mean values of $K$ per ring were then used to determine leaf area index with Lang's method (equation 2), using five, four and three rings, respectively.

\subsubsection{Hemispherical photographs}

\section{- The shootings}

In each study area, four photographs were taken in uniformly overcast sky conditions, precisely centred on the zenith, at the same height as PCA measurements. We used a 35-mm single-lens camera equipped with a $8-\mathrm{mm}$ F/4 fish-eye lens (Sigma Corporation, Tokyo, Japan). For a better contrast, we opted for an orthochromatic film offering high sensitivity in the blue region of the solar spectrum (Agfaortho 25, Agfa-Gevaert, Leverkusen, Germany). After a series of tests, the exposure parameters were determined by measuring the incident radiation in an open area with a PAR (photosynthetically active radiation) sensor. For instance, these parameters varied from $1 / 15 \mathrm{~s}$ and $\mathrm{F} / 5.6$ (dark overcast sky) to $1 / 60 \mathrm{~s}$ and $\mathrm{F} / 8$ (bright overcast sky), i.e. overexposed by three to four stops compared with an exposuremeter placed in the same situation. This operating mode ensured a correct exposure of the film. Variation in exposure can cause considerable errors in the determination of the structural parameters of a canopy [8]. The film was processed using a high-contrast developer (Kodak HC 110, dilution B, 6.5 $\min$ at $20^{\circ} \mathrm{C}$ ).

\section{- Processing}

The negatives were inverted and digitized by Kodak's 'Photo CD' consumer photographic system. The image file that was used had a $512 \times 680$ pixel resolution with 256 grey levels (8-bit TIFF image). This operating mode eliminated the printing stage that may be the cause of inaccuracy. Data processing was done using ANALYP software developed by V. Garrouste (CIRAD Montpellier, France). An initial centring process appeared necessary because the images were more or less shifted when digitized. The image was analysed pixel by pixel. Then, a threshold level (the same for all the pictures) was chosen: if a pixel had a grey scale less than 128 of the 256 grey levels, it was considered to be a gap. The most subjective point was obviously the centring process because the horizon (i.e. the edge of images) was mostly unseen. An automatic procedure was performed by the software but an uncertainty about a few pixels probably remained. On the contrary, the choice of a threshold value caused no difficulty, the images showing a high contrast level.

The software provided estimates of the gap fraction for various sectors of the images.

- Dividing over zenith angle. To compute the gap fraction of each ring with constant accuracy, independent of the considered angle, we considered rings centred on 10 , $25,35,45,55$ and $65^{\circ}$ and decreasing in amplitude from zenith to horizon $\left(20,10,10,5,5\right.$ and $5^{\circ}$, respectively).

- Dividing over azimuth. The gap fraction was determined i) averaged over azimuth $\left(360^{\circ}\right)$, ii) considering $90^{\circ}$ sectors, iii) $45^{\circ}$ sectors and iv) $22.5^{\circ}$ sectors.

The $K$ value for each ring was calculated in each case, first using the gap fraction averaged over azimuth $\left(K_{\mathrm{a}}\right)$, and then from the logarithmic average of the gap fractions obtained considering sectors of $90^{\circ}\left(K_{90}\right), 45^{\circ}\left(K_{45}\right)$ and $22.5^{\circ}\left(K_{22}\right)$.

Such an approach requires the estimation of a low limit for the value of the gap fraction: in the case of completely black sectors (with zero white pixel), the logarithm of the gap fraction is undefined. Considering the size of these small sectors (700 and 1400 pixels on average for $22.5^{\circ}$ and $45^{\circ}$ ) and the fact that the gap fraction estimates were rounded off to $0.1 \%$ by the software, we allocated to all black sectors a gap fraction of $0.05 \%$. Leaf area index values were then computed using Lang's method (equation 2) and their variation was tested by modifying the value allocated to black sectors.

\subsection{Leaf angle distribution}

We used two data sets from the Compiègne forest, concerning young beech trees grown in contrasting light conditions: shaded, intermediary and open area. The leaf angle distribution in intermediary light conditions (relative available radiation of about $50 \%$ in PAR) was established in a previous work [21] by measuring with a protractor leaf inclination from the upper part of three crowns. For the two other light conditions, leaf angle measurements were performed using a magnetic digitizing technique, applied to shaded (relative radiation of about $5 \%$ ) and sunny branches [22]. The three distribu- 
tions of leaf inclination were divided into six classes $i$ of $15^{\circ}$ each and the $G(\alpha \mathrm{i}, \theta)$ function was calculated for all classes i, assuming leaves to be randomly orientated in azimuth [23]. We calculated the stand specific $G$ function as follows:

$$
G_{\mathrm{stand}}(\theta)=\sum_{\mathrm{i}=1}^{6} F \mathrm{q}\left(\alpha_{\mathrm{i}}\right) G\left(\alpha_{\mathrm{i}}, \theta\right)
$$

where $F \mathrm{q}\left(\alpha_{\mathrm{i}}\right)$ is the proportion of the total leaf area in the class number $\mathrm{i}$.

\section{RESULTS}

\subsection{Semi-direct estimation of leaf area index}

At the shoot level, the allometric relationship between the shoot leaf area $\left(L_{\mathrm{as}}, \mathrm{m}^{2}\right)$ and the shoot length $(l, \mathrm{~m})$ was:

$L_{\text {as }}=0.0055 \quad$ if $l<0.015$ (short shoots)

$L_{\text {as }}=0.0084+0.0367 l \quad$ if $l>0.015\left(r^{2}=0.80, n=181\right)$

At the branch scale, relationships between branch leaf area $\left(L_{\mathrm{ab}}, \mathrm{m}^{2}\right)$ and branch diameter $(D, \mathrm{~m})$ were as follows:

1- and 2-year-old branches:

$$
\begin{aligned}
& L_{\mathrm{ab}}=25.1 D^{1.136} \\
& \left(r^{2}=0.71, n=49\right)
\end{aligned}
$$

3- and 4-year-old branches: $\quad L_{\mathrm{ab}}=447 D^{1.634}$

$$
\left(r^{2}=0.72, n=77\right)
$$

5- and 6-year-old branches: $\quad L_{\mathrm{ab}}=1067 D^{1.744}$

$$
\left(r^{2}=0.77, n=46\right)
$$

7-year-old branches and older: $L_{\mathrm{ab}}=3788.3 D^{2}$

$$
\left(r^{2}=0.78, n=49\right)
$$

At the scale of the whole tree, leaf area $\left(L_{\mathrm{at}}, \mathrm{m}^{2}\right)$ was calculated from the tree basal area at breast height $\left(B_{\mathrm{a}}, \mathrm{m}^{2}\right)$ and from the height to the base of the live crown $\left(H_{\mathrm{cb}}, \mathrm{m}\right)$ :

$$
L_{\mathrm{at}}=8730 B_{\mathrm{a}} \exp \left(-0.285 H_{\mathrm{cb}}\right)\left(r^{2}=0.866, n=26\right)
$$

Using these relationships, we obtained leaf area index values of 7.5 and 6.7 for plots 1 and 2, respectively. These values are close to those reported in the literature for young dense beech stands [2].

\subsection{Gap fraction $T(\theta)$}

Figure 1 shows the gap fraction at various zenith angles, measured in the two plots with the PCA $(n=10)$ and hemispherical photographs $(n=4)$. Data from the PCA show a regular decrease in both gap fraction and data dispersion with increasing zenith angle. This trend is not so clear with hemispherical photographs, this being

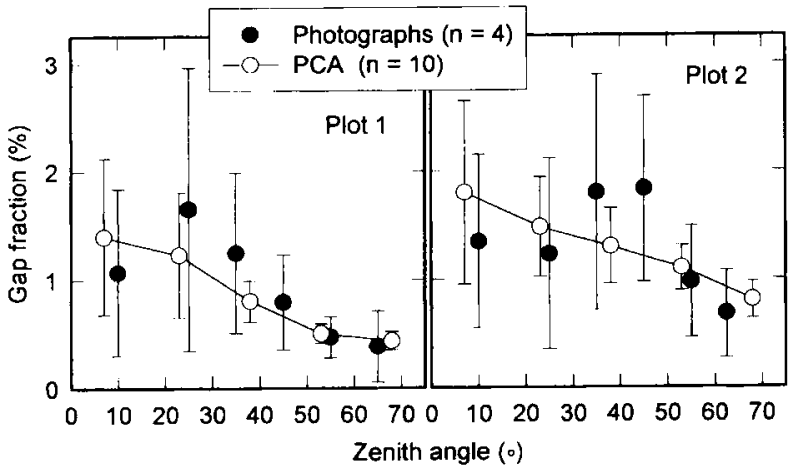

Figure 1. Gap fraction values obtained on two beech stands at various zenith angles with a Li-Cor Plant Canopy Analyzer (PCA) and with hemispherical photographs. Error bars represent the standard deviation of the populations.

mostly due to variability between photographs. This might be explained by the small number of photographs taken and by differences in the width of the rings that were used in the two techniques. Nevertheless, discrepancies between the two data sets are very low, never exceeding $0.5 \%$.

\section{3. $K(\theta)$ function}

Figure 2 represents the values of $K(\theta)$ obtained using the PCA and hemispherical photographs with all four previously mentioned procedures: $K_{\mathrm{a}}, K_{90}, K_{45}$ and $K_{22}$. When the gap fraction is integrated over azimuth $\left(K_{\mathrm{a}}\right), K$ values obtained with both methods are very close. On the contrary, dividing rings into azimuth sectors systematically increases $K$ values. In both plots, it is clear that dividing all rings into four elements only $\left(K_{90}\right)$ takes into account a large part of the variability in azimuth of the gap fraction. A sharper analysis $\left(K_{45}\right.$ and $\left.K_{22}\right)$ leads to a smaller but non-negligible increase in $K$.

\subsection{Leaf area index estimation}

Table I presents estimates of leaf area index obtained from both tree allometrics and indirect methods (equations 1 and 2). As expected, the results are similar for the PCA with five rings and for the photographic technique when the gap fraction is averaged over azimuth $\left(K_{\mathrm{a}}\right)$. These two estimates are far below those resulting from tree allometrics (by 1.7 to 1.9). Considering smaller sectors when processing the hemispherical photographs $\left(K_{90}\right.$ 


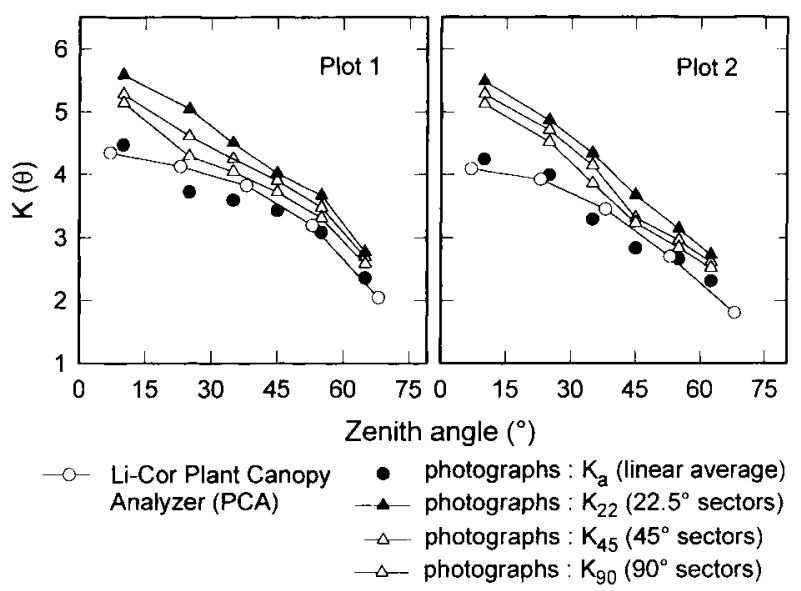

Figure 2. $K(\theta)$ functions obtained on two beech stands at various zenith angles with a Li-Cor Plant Canopy Analyzer (PCA) and with hemispherical photographs according to several calculation modes (see text).

to $K_{22}$ ) results in a regular increase in leaf area index (by 1.1 at maximum). These results tend to show that the underestimation observed when considering five rings results, at least partially, from an inappropriate use of the random model.

Our estimations with a PCA discarding one or two rings are in agreement with observations made by Dufrêne and Bréda [9]: leaf area index rises by less than 1 if a single ring is disregarded (i.e. +12 and $+14 \%$ in our two plots) and by nearly 1.5 if the two lowest rings are neglected $(+25$ and $+27 \%$, respectively). If we take as a reference the estimation from tree allometrics, the best PCA estimation in our plots is obtained only when three rings are considered.

These results were obtained using a gap fraction of black sectors equal to $0.05 \%$. We have tested the incidence of this arbitrary value on leaf area index estimation

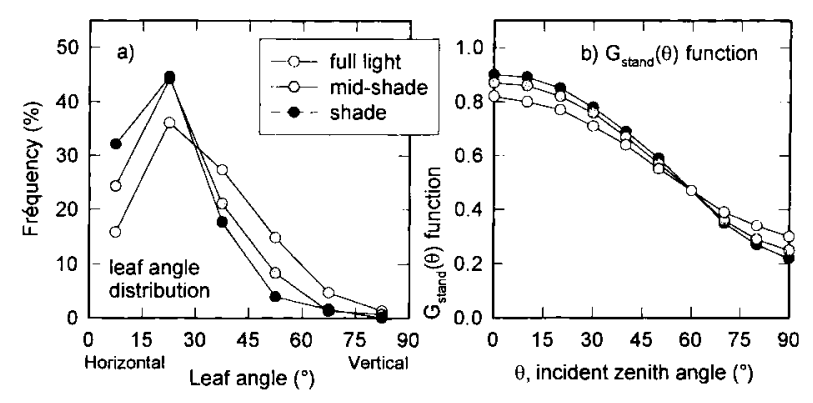

Figure 3. (a) Leaf angle distribution of young beech trees. Three situations are considered: well exposed, partly shaded and shaded leaves. (b) $G(\theta)$ function corresponding to these three light conditions.

by varying it from 0.01 to $0.09 \%$ (in $K_{45}$ option, plot 1 ). The impact was moderate: $L$ values ranging from 6.7 to 6.4 in this case.

\section{5. $\mathbf{G}_{\text {stand }}(\theta)$ function: measured versus calculated values}

Leaf angle distributions measured in contrasting light conditions were very close, resulting in similar $G_{\text {stand }}(\theta)$ functions (figure 3). Our pole stands were growing in open areas and consequently having few shade leaves, so we opted for the distribution observed in the intermediate light condition. Considering the little difference observed between the three distributions, the error on $G_{\text {stand }}(\theta)$ function is expected to be low.

Figure 4 compares these values of $G_{\text {stand }}(\theta)$, derived from the measured leaf angle distribution, with those calculated with the PCA (five, four and three rings) and hemispherical photographs (sectors $22^{\circ}$ ): $G$ was computed as the ratio of $K$ per estimated $L$ (equation 1). The result is globally satisfying and shows that both PCA

Table I. Values of leaf area index obtained in the two plots using all techniques presented in this study.

\begin{tabular}{|c|c|c|c|c|c|c|c|c|}
\hline & \multirow[t]{2}{*}{ Allometry } & \multicolumn{3}{|c|}{ Plant Canopy Analyzer } & \multicolumn{4}{|c|}{ Hemispherical photographs* } \\
\hline & & $\begin{array}{l}\text { Five } \\
\text { rings }\end{array}$ & $\begin{array}{l}\text { Four } \\
\text { rings }\end{array}$ & $\begin{array}{l}\text { Three } \\
\text { rings }\end{array}$ & $\begin{array}{c}\text { Linear } \\
\text { average }\end{array}$ & $\begin{array}{c}90^{\circ} \\
\text { sectors }\end{array}$ & $\begin{array}{c}45^{\circ} \\
\text { sectors }\end{array}$ & $\begin{array}{l}22.5^{\circ} \\
\text { sectors }\end{array}$ \\
\hline Plot 1 & 7.5 & 5.6 & 6.4 & 7 & 5.6 & 6.1 & 6.5 & 6.7 \\
\hline Plot 2 & 6.7 & 4.9 & 5.5 & 6.2 & 5 & 5.5 & 5.7 & 6.1 \\
\hline
\end{tabular}

\footnotetext{
* Gap fraction in black sectors being set to $0.05 \%$.
} 


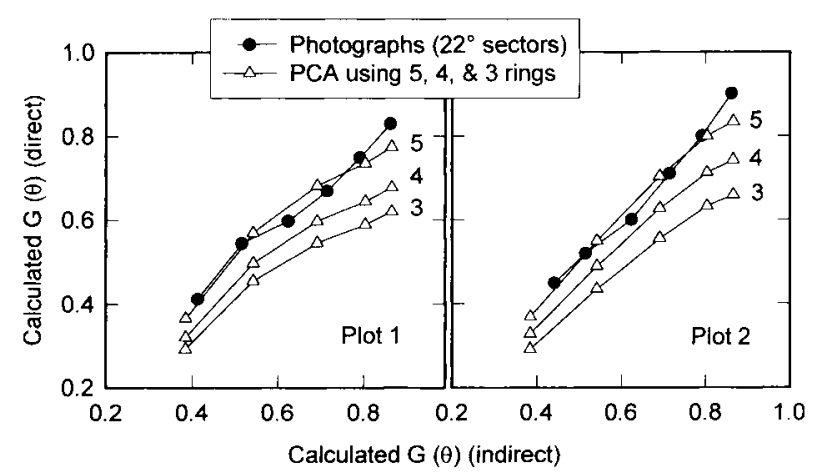

Figure 4. Comparison of direct (computed from leaf inclination distribution) and indirect (from gap fraction measurements) $G(\theta)$ functions obtained with hemispherical photographs (sectors of $22.5^{\circ}$ ) and with a Li-Cor Plant Canopy Analyzer (PCA) considering five, four or three rings.

(using five rings) and photographs provide reliable information on $G_{\text {stand }}(\theta)$ function. In return, PCA underestimates $G_{\text {stand }}(\theta)$ when one or two rings are neglected. Since $G_{\text {stand }}(\theta)$ values derived from measurements can be considered as reliable, the rise in $L$ values observed when rings are omitted results from of an error in the estimated values of $G_{\text {stand }}(\theta)$ : leaves are supposed to be more erect than they effectively are and this, for a given transmitted radiation, results in an increase in $L$. This bias in $G_{\text {stand }}(\theta)$ function is explained by observing the shape of the function $K(\theta)$ which is the same as that of $G(\theta)$ (equation 1). When the leaf angle distribution is planophile, $G_{\text {stand }}(\theta)$ is not exactly linear and approximates a cosinus function for low $\theta$ values. The use of Lang's method when observations are restricted to low values of $\theta$ causes a non-negligible error on the estimation of the slope of the $K(\theta)$ function.

\subsection{Estimation of the error due to leaf angle distribution}

Defining $K_{5}(1), K_{4}(1), K_{3}(1)$ as the estimations, with Lang's method, of $K$ function for an angle of 1 radian with five, four and three rings, respectively, the relative error made on $L$ if one ring $\left(E_{1}\right)$ or two rings $\left(E_{2}\right)$ are discarded, is equal to the relative error made on the associated $G$ function (equation 1 ):

$$
\begin{aligned}
& E_{2}=\frac{2 K_{3}(1)-2 K_{5}(1)}{2 K_{5}(1)}=\frac{G_{3}(1)-G_{5}(1)}{G_{5}(1)} \\
& E_{1}=\frac{2 K_{4}(1)-2 K_{5}(1)}{2 K_{5}(1)}=\frac{G_{4}(1)-G_{5}(1)}{G_{5}(1)}
\end{aligned}
$$

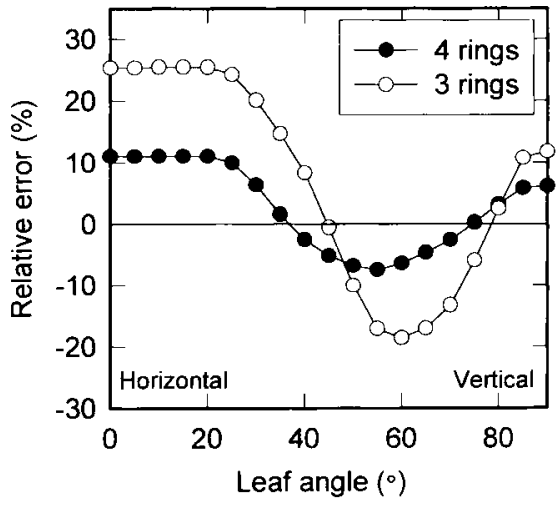

Figure 5. Theoretical relative error on leaf area index estimation for various leaf angles when considering three or four rings instead of five.

We computed this relative error in the theoretical case of a canopy composed of leaves having all the same inclination.

For $\alpha$ ranging from 0 to $90^{\circ}$, the function $G(\alpha, \theta)$ was calculated for the $\theta$ angles corresponding to the five rings of the PCA $\left(7,23,38,53\right.$ and $\left.68^{\circ}\right)$. A linear regression of $G$ on $\theta$, taking into account five, four and three rings, respectively, enabled us to interpolate $G_{5}(1), G_{4}(1)$, $G_{3}(1)$, and to compute $E_{1}$ and $E_{2}$, respectively (equation 3).

Figure 5 illustrates the expected error on L estimation if one or two rings are neglected. The higher bias corresponds to horizontal leaves: the error remains constant at about +11 and $+25 \%$ for one and two omitted rings, respectively. Beyond $30^{\circ}$, the error largely fluctuates with leaf angle, making difficult a realistic estimation of the error. The best accuracy is obtained at about 40 and $75^{\circ}$. Between these two values, removing rings may cause an underestimation of $L$ up to $-7 \%$ (one ring) and $-15 \%$ (two rings).

\subsection{Directional variability of the gap fraction and dispersion index}

Figure 6 shows the coefficients of variation of the gap fractions obtained, for all rings, by the above-mentioned methods. Curves 1 and 2 reflect the spatial dispersion of data only. The rise observed from curve 3 to curve 5 illustrates the importance of the directional variability of the gap fraction. According to the size of the azimuth sectors, the quasi-random model partly takes into account clumping effects. The ratio of $L$ estimated using the random 


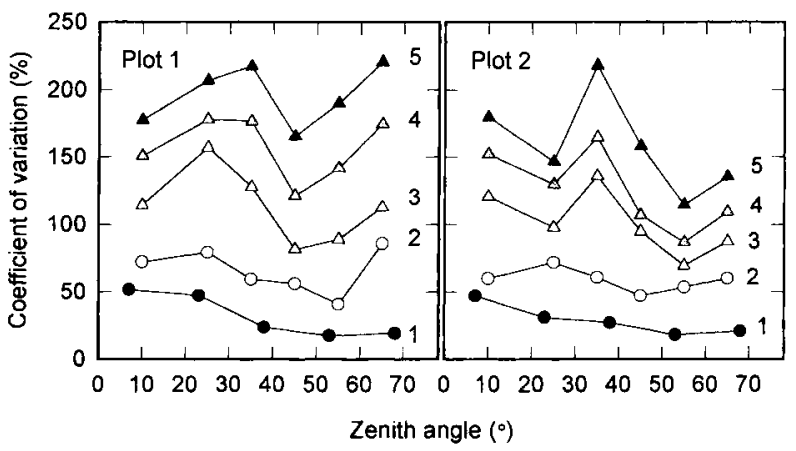

Figure 6. Dispersion of gap fraction data at various zenith angles in the following cases: 1) Li-Cor Plant Canopy Analyzer (PCA); 2) photographs using $360^{\circ}$ sectors; 3) photographs using $90^{\circ}$ sectors; 4) photographs using $45^{\circ}$ sectors; and 5) photographs using $22.5^{\circ}$ sectors.

model to $L$ estimated from allometry enables the assessment of a leaf dispersion index $\mu$. It was found to be equal to 0.75 in both stands.

Figure 4 shows that the random model (PCA with five rings) provides reliable information on $G_{\text {stand }}(\theta)$ function, close to that obtained with the quasi-random model (hemispherical photographs). Consequently, the relative error made on the $K$ function with the random model seems independent of the $\theta$ value: it appears correct to use initially a constant dispersion index irrespective of the $\theta$ value.

\section{DISCUSSION}

\subsection{Quasi-random model and canopy structure}

Our results emphasize the quasi-random model proposed by Lang and Xiang Yueqin [14] as a simple approach to improve $L$ estimation: several authors pointed out that this procedure was well adapted to heterogeneous canopies $[4,10,14]$. In our dense and apparently homogeneous stands, it provided an explanation for the underestimation of the leaf area index (about 1.1) obtained with the random model. Thus, the clumping effect should be considered in all forest types.

\subsection{Underestimation of $L$ by the PCA and omission of one or two rings}

Many authors $[6,9,10]$ stated that the PCA underestimated the gap fraction in the lowest rings and opted for neglecting them. For this, they invoked a sensitivity of the PCA to scattered light, that presumably increased together with $\theta$ values. The results of this study contradict this assumption. A comparison of gap fraction measurements made with a PCA and hemispherical photographs did not revealed large discrepancies between the two methods, and in particular showed no bias linked with high $\theta$ values.

Moreover, it appears that only a drastic overestimation of the gap fraction could result in a decrease in $L$ of about $25 \%$ : if $T$ is the gap fraction measured with the PCA (overestimated), it is necessary, to increase $K$ of $25 \%$, to consider a real gap fraction equal to a $T$ power of 1.25 ; for instance $0.3 \%$ instead of $1 \%$. In this case, the PCA should overestimate the gap fraction by almost $200 \%$, which seems unrealistic if we consider that the PCA operates only in the blue region of the solar spectrum. We think that a hypothetical sensitivity of the PCA to scattered light is insufficient to explain the large $L$ underestimates reported in the literature.

Our observations also show that the error made on $K$ function by the PCA is not restricted to the lowest rings (figure 2) and results from an inappropriate use of the Poisson model. The increase in $L$ observed when considering clumping effects (quasi-random model), i.e. about $20 \%$, is rather close to that obtained by neglecting one or two rings with the PCA $(+11$ and $+25 \%$, respectively, for horizontal leaves). Practically, these two errors compensate for one another so that data obtained using three or four rings often show an excellent correlation with direct measurements of $L$. However, this procedure is dangerous and users have to be warned not to apply it blindly.

The method proposed by Lang [13] required initially direct solar radiation by using the sun's beam as a probe. It was recommended to assess the regression parameters using multiple measurements of the $K$ function, for $\theta$ values distributed above and below $45^{\circ}$. In these conditions, the error made on leaf area index when assuming a linear $K$ function was moderate $(<6 \%)$. Unfortunately, this error largely increases if we now consider $\theta$ values ranging from 7 to $53^{\circ}$ (PCA with four rings) or 7 to $38^{\circ}$ (three rings only), especially for horizontally distributed leaves. Omitting one or two rings is particularly dangerous because it has variable effects, depending on leaf angle distribution. For instance, in coniferous stands (Pinus banksiana Lamb, and Picea mariana Mill.), Chen [5] reported a decrease of about $6 \%$ in leaf area index estimates when neglecting two rings, contrary to the most commonly observed situation. The present study suggests that the reason for that is related to the needle angle distribution (erected, so yielding the error shown in figure 5) and not to a lower light scattering as suggested by Chen [5]. It is therefore difficult to compare leaf area index 
estimates obtained with three or four rings if leaf angle distributions are unknown.

\subsection{Respective advantages of these indirect techniques}

This study underlines the need for reliable information on the directional distribution of the gap fraction. The hemispherical photographs technique appeared well adapted to our young plots, providing satisfying estimates of the gap fraction from every sector of the sky. However, this technique is successful only if the considered sectors are small enough to be homogeneous, with randomly distributed leaves, and if the size of a pixel is close to that of a leaf on the image. Thus, a study in tall canopies of $20 \mathrm{~m}$ high or more will require a better resolution, which is now technically available. In the present study, the moderate tree height $(8$ and $11 \mathrm{~m})$ partly ensured the quality of the estimates despite a moderate resolution $(512 \times 680$ pixels). This also explains why a division into sectors of $90^{\circ}$ was sufficient to take into account the directional variability of the gap fraction.

In other respects, the use of the quasi-random model requires an estimation of the gap fraction in sky sectors of the same size. The area of the rings used in the PCA varies considerably, the lowest ring being seven times larger than the upper one. This causes an underestimation of the $K(\theta)$ function at the lowest rings. Concerning this, our work showed that the coefficient of variation of the gap fractions derived from photographs was more or less independent of $\theta$ values whereas those from the PCA significantly decreased with $\theta$ (figure 6). We think that the PCA is not really adapted to quantify heterogeneity in canopies. In return, it has the enormous advantage of providing, with a single pass, averaged values of the gap fraction at various zenith angles. These values are reliable because they are obtained using a wide view angle.

In conclusion, we believe that a better accuracy could be reached if several techniques were pooled together. A dispersion index assessed with the Demon device could be used to rectify the $K(\theta)$ function from PCA.

Data of transmitted direct radiation using the Demon device, computed with the method proposed by Lang and colleagues $[12,15]$ should make it possible to quantify the relative error made on $K$ due to the random model. The Demon measures continuously over a transect the direct radiation transmitted to the ground (1 024 measurements for $34 \mathrm{~s}$ ). Lang suggests initially averaging the gap fraction over a distance of about ten times the length of a leaf. Then, the logarithms of these gap fractions are calculated and averaged over the whole transect.
We consider that this relatively simple method should allow the estimation of a reliable dispersion index $(\mu)$. This parameter only reflects the foliage clustering between crowns, neglecting any clustering at smaller scales; however, this is probably the principal drawback with regard to the Poisson model. If this dispersion index remains relatively stable when $\theta$ varies, as shown here, a single pass should be sufficient to estimate it, for whatever sun elevation. This dispersion index could then be used to rectify the $K(\theta)$ function measured with the PCA. We think that such an approach, even if it is time-consuming, should be tested because it might substantially improve the accuracy of the $L$ estimation.

Acknowledgements: the authors acknowledge P. Siband and V. Garrouste (CIRAD Montpellier) who kindly provided their 'ANALYP' image analysis software. Thanks are due to Dr. A.R.G. Lang who reviewed this paper and greatly contributed to improving the manuscript.

\section{REFERENCES}

[1] Anderson M.C., Studies of the woodland light climate. I. The photographic computation of light conditions, J. Ecol. 52 (1964) 27-41.

[2] Bartelink H.H., Allometric relationship for biomass and leaf area of beech (Fagus sylvatica L.), Ann. Sci. For. 54 (1997) 39-50.

[3] Bonhomme R., Chartier P., The interpretation and automatic measurement of hemispherical photographs to obtain foliage sunlit area and gap frequency, Israelian J. Agric. Res. 22 (1972) 53-61.

[4] Chason J., Baldocchi D., Huston M., A comparison of direct and indirect methods for estimating forest leaf area, Agric. For. Meteorol. 57 (1991) 107-128.

[5] Chen J.M., Optically-based methods for measuring seasonal variation of leaf area index in boreal conifer stands, Agric. For. Meteorol. 80 (1996) 135-163.

[6] Chen J.M., Black T.A., Measuring leaf area index of plant canopies with branch architecture, Agric. For. Meteorol. 57 (1991) 1-12.

[7] Chen J.M., Cihlar J., Plant canopy gap size analysis theory for improving optical measurements of leaf area index of plant canopies, Appl. Optics 34 (1995) 6211-6222.

[8] Chen J.M., Black T.A., Adams R.S., Evaluation of hemispherical photography for determining plant area index and geometry of a forest stand, Agric. For. Meteorol. 56 (1991) 192-143.

[9] Dufrêne E., Bréda N., Estimation of deciduous forests leaf area index using direct and indirect methods, Oecologia 104 (1995) 156-162.

[10] Fassnacht K.S., Gower S.T., Norman J.M., McMurtrie R.E., A comparison of optical and direct methods for estimating 
foliage surface area index in forests, Agric. For. Meteorol. 71 (1994) 183-207.

[11] Gregoire T., Valentine H.T., Furnival G.M., Sampling methods to estimate foliage and other characteristics of individual trees, Ecology 76 (4) (1995) 1181-1194.

[12] Lang A.R.G., Leaf area and average leaf angle from transmittance of direct sunlight, Aust. J. Bot. 34 (1986) 349-355.

[13] Lang A.R.G., Simplified estimate of leaf area index from transmittance of the sun's beam, Agric. For. Meteorol. 41 (1987) 179-186.

[14] Lang A.R.G., Xiang Yueqin Y., Estimation of leaf area index from transmission of direct sunlight in discontinuous canopies, Agric. For. Meteorol. 37 (1986) 229-243.

[15] Lang A.R.G., McMurtrie R.E., Benson M.L., Validity of surface area indices of Pinus radiata estimated from transmittance of the sun's beam, Agric. For. Meteorol. 57 (1991) $157-170$.

[16] Li-Cor, LAI 2000 Plant Canopy Analyzer. Technical report \# 102, Li-Cor, Lincoln, NE, USA, 1990, 12 p.

[17] Li-Cor, LAI-2000 Plant Canopy Analyzer. Operating Manual, Li-Cor, Lincoln, NE, USA, 1992, 90 p.

[18] Neumann H.H., Den Hartog G., Shaw R.H., Leaf area measurements based on hemispherical photographs and leaf-litter collection in a deciduous forest during autumn leaf-fall, Agric. For. Meteorol. 45 (1989) 325-345.
[19] Nilson T., A theoretical analysis of the frequency of gaps in plant stands, Agric. For. Meteorol. 8 (1971) 25-38.

[20] Norman J.M., Campbell G.S., Canopy structure, in Pearcy R.W., Ehleringer J., Mooney H.A., Rundel P.W., (Eds.), Plant Physiological Ecology, Field Methods and Instrumentation, Chapman \& Hall, New York, 1989, pp. $301-325$.

[21] Planchais I., Pontailler J.Y., Application d'un modèle de pénétration de la lumière à une jeune plantation de hêtre avec abri latéral, Ann. Sci. For. 54 (1997) 243-260.

[22] Planchais I., Sinoquet H., Foliage determinants of light interception in sunny and shaded branches of Fagus sylvatica (L.), Agric. For. Meteorol. 89 (1998) 241-253.

[23] Reeve J.E., Appendix on derivation of formulae, New Phytol. 59 (1960) 7-8.

[24] Sinoquet H., Modélisation des échanges radiatifs de courte longueur d'onde dans certains couverts hétérogènes, thesis, Ina-PG, Paris, 1988.

[25] Strachan I.B., Mc Caughey J.H., Spatial and vertical Leaf Area Index of a deciduous forest resolved using the LAI2000 Plant Canopy Analyzer, For. Sci. 42 (2) (1996) 176-181.

[26] Welles J.M., Norman J.M., An instrument for direct measurement of canopy architecture, Agron. J. 83 (1991) $818-825$. 